http://jmscr.igmpublication.org/home/ ISSN (e)-2347-176x ISSN (p) 2455-0450 crossref DOI: https://dx.doi.org/10.18535/jmscr/v8i8.02

\title{
Assessment of Bronchiectasis with BSI score and Correlation with Quality of Life by St George Respiratory Questionnaire
}

\author{
Authors \\ Varughese Prince $^{1 *}$, Jahangir $S^{2}$, Divya Mary ${ }^{3}$ \\ ${ }^{1}$ Assistant Professor, Pondicherry Institute of Medical Sciences, Pondicherry \\ ${ }^{2,3}$ Senior Resident, Pondicherry Institute of Medical Sciences, Pondicherry \\ *Corresponding Author \\ Varughese Prince
}

\begin{abstract}
Introduction: Bronchiectasis is a chronic suppurative lung disease having greater inverse impact on the patient's quality of life. The BSI score is a multidimensional grading system capable of classifying the severity of bronchiectasis according to its prognosis. The St. George Respiratory Questionnaire is a selfadministered health-related quality of life questionnaire containing 50 items and 76 weighted responses measuring the quality of life of the patients with respiratory morbidity in three dimensional components namely Symptoms, Activity, and Impacts.

Objectives: To compare the severity of bronchiectasis as measured by BSI score with the QOL measured by $S G R Q$ scores.

Materials and Methods: The prospective observational study was conducted among 82 patients attending to the Department of Pulmonary Medicine, Pondicherry Institute of Medical Sciences, with stable bronchiectasis during the period October 2016 to April 2018. A proforma was used to collect the socio-demographic and clinical variables including age, gender, severity of dyspnoea, history of smoking and number of exacerbations per year. The patient was then subjected to routine laboratory investigations, spirometry, HRCT and sputum culture. BSI score for severity and SGRQ score for QOL were computed for each patient and correlated.

Results: Majority of the study participants belonged to the $50-69$ years age group (56.1\%) and female participants (57.3\%) compared to the males (46.3\%). The mean BSI scores obtained by the study participants $(n=82)$ was $10.63 \pm 4.26$ respectively. Most of the study participants $(68.3 \%)$ were classified as severe bronchiectasis than mild and moderate categories as $8.5 \%$ and $23.2 \%$ respectively. There was a highly significant correlation between the BSI score and the SGRQ score percentage.

Conclusion: The study showed that as the severity scores increased there was a derangement in the quality of life as recorded by the SGRQ.

Keywords: Bronchiectasis severity Index, BSI, St. George Respiratory Questionnaire (SGRQ), Bronchiectasis.
\end{abstract}

\section{Introduction}

Bronchiectasis is a debilitating respiratory disease caused by irreversible dilatation of airway leading to chronic cough, sputum production and recurrent infective exacerbations. Continuous insult to the respiratory anatomy by vicious cycle of infection and inflammation arising from a number of causes either acquired or inherited, leads to structural 
abnormalities including abnormal chronic dilatation of bronchi termed as Bronchiectasis. ${ }^{[1]}$ High resolution computed tomography (HRCT) has made the identification of three types of morphological forms of bronchiectasis which include Cylindrical or tubular, varicose and cystic bronchiectasis. Bronchiectasis is etiologically classified into cystic fibrosis and non-cystic fibrosis bronchiectasis (NCFB). NCFB may manifest due to various causes including congenital and acquired, with the later more frequent. Congenital causes include primary immunodeficiencies, situs in versus, primary ciliary dyskinesia, etc. Corticosteroid-dependent asthma, Pulmonary Tuberculosis, lobar pneumonia, inhaled foreign bodies; pulmonary aspiration, allergic broncho-pulmonary aspergillosis and bronchial neoplasia are the major acquired causes of NCFB. ${ }^{[1]}$ Bronchiectasis transferring into an important public health problem with advent of urbanisation and newer respiratory morbidities causing damage to the bronchial track, the need for a routinely used clinical predictive tool for assessment of its severity was felt essential. Grading the severity would help in targeting treatment to the patients most likely to benefit and improving their quality of life. Bronchiectasis Severity Index (BSI) is a multidimensional grading system capable of classifying the severity of bronchiectasis according to its prognosis. $\mathrm{BSI}^{[2]}$ is a seven-point score that identifies patients with NCFB at risk for future mortality, hospitalization and exacerbations.

Health-related quality of life (HRQL) measurement scales are objective instruments to measure directly the impact of disease on the diseased patient's dayto-day life. Bronchiectasis is a disease which has higher debilitating influence on the life of the patient and measurement of the same would be of immense help in determining the cost of prescribed medications, the duration of treatment, the social influence on the treatment compliance and many other factors.

The St. George's Respiratory Questionnaire is a self-administered health-related quality of life questionnaire containing 50 items and 76 weighted responses measuring the quality of life of the patients with respiratory morbidity in three dimensional components namely Symptoms, Activity, and Impacts. ${ }^{[3]}$

The present study was designed to relate the bronchiectasis severity indices with the impact of the disease in real time using a standardized tool for measuring the quality of life. The essence of the research would be bringing out the internal validity of the SGRQ tool in predicting the impact the disease has on various facets of the patients' daily life as the severity of the disease increases. The scores measuring severity also contain social variables like number of admissions and exacerbations which definitely have an impact on the quality of life exhibited by the patients living with bronchiectasis. Hence this research was the need of the hour to take multi-dimensional conceptualisation in grading the well documented debilitating respiratory morbidity namely bronchiectasis.

\section{Aim and Objectives}

To obtain BSI score and to administer SGRQ to the patients enrolled in the study. To correlate BSI score in predicting SGRQ health-related quality of life score.

\section{Materials and Methods}

The prospective observational study was conducted among 82 patients attending to the Department of Pulmonary Medicine, Pondicherry Institute of Medical Sciences, with stable bronchiectasis during the period October 2016 to April 2018. A proforma was used to collect the socio-demographic and clinical variables including age, gender, severity of dyspnoea, history of smoking and number of exacerbations per year. The patient was clinically examined for anthropometric and other clinical signs associated with bronchiectasis and then subjected to routine laboratory investigations, spirometry, HRCT and sputum culture, BSI score for severity and SGRQ. Approval from the Institutional Ethics Committee was obtained prior to start of the study. 


\section{Exclusion Criteria}

1. Active mycobacterial disease

2. HIV infections

3. Malignancies of Lung

4. IPF with secondary traction bronchiectasis

5. Patients on long term antibiotics

The clinical, spirometry, bacteriological and radiology parameters collected for each patient was used to compute BSI score.

The BSI incorporates 9 variables:

1. Age:
a. less than 50 years ( 0 points);
b. 50-69 years ( 2 points),
c. $70-79$ years (4 points),
d. more than 80 years ( 6 points)

2. Body mass index (BMI):

a. less than 18.5 (2 points),

b. more than 18.5 (0 points)

3. FEV1\% predicted:
a. less than $80 \%$ ( 0 points),
b. $50-80 \%$ (1 point),
c. $30-49 \%$ ( 2 points),
d. less than $30 \%$ (3 points)

4. Hospital admission in previous year:

a. no (0 points),

b. yes (5 points)

5. Exacerbations in previous year:
a. $0-2$ (0 points),
b. 3 or more ( 2 points)

6. MRC dyspnea score:
a. 1-3 (0 points),
b. 4 (2 points),
c. 5 (3 points)

7. Pseudomonas aeruginosa colonization:
a. no ( 0 point $)$,
b. yes (3 points)

8. Colonization with other microorganisms:
a. no (0 point),
b. yes (1 point)

9. Radiological severity

(more than 3 lobes involved or cystic bronchiectasis):
a. no (0 points)
b. yes (1 point)

Scoring: An overall score is derived as a sum of the scores for each variable and it may range from 0 to 26 points

According to the overall score value, the patients with bronchiectasis are classified into 3 BSI classes:

A. low BSI score (overall score 0-4 points),

B. intermediate BSI score (overall score 5-8 points) and

C. high BSI score (overall score 9 or more points)

The St George Respiratory Questionnaire has weighted responses for symptoms, activity and impacts. St. George Respiratory Questionnaire was translated in local language and self-administered to the patients. It assessed the QOL by weighted responses for symptoms, activity and impacts.

\section{Statistical Analysis}

The data entry and analysis were done using SPSS version 21.0 [Statistical software for social sciences]. The summary measures were expressed using tables and graphs using percentages and frequencies for categorical variables and mean \pm SD for numerical continuous and discrete variables. The statistical significance between two means was tested using Independent Student t-test and between categorical variables was tested using Chi-square test. For all statistical tests of significance, a p-value of less than 0.05 was considered significant within $95 \%$ confidence limits.

\section{Results}

The prospective observational study was conducted by following-up 82 patients, diagnosed to have bronchiectasis clinically and radiologically, attending to the department of Pulmonary Medicine for evaluation and treatment. The mean age of the study participants was $55.6 \pm 14.7$ years. There were a comparatively higher proportion of female participants $(57.3 \%)$ with bronchiectasis included in the study compared to the males $(46.3 \%)$. There was no significant $(\mathrm{p}=0.57, \mathrm{df}=3)$ variations in age distribution between males and females. Majority of the study subjects had MMRC breathlessness grades III and IV (75.6\%, $\mathrm{n}=62)$ when compared to the lower grades indicating that there was more 


\section{JMSCR Vol||08||Issue||08||Page 06-11||A ugust}

parenchymal damage or obstructive airway disease for most of the participants. The patients were interviewed about the number of episodes of severe breathing difficulty they had in the past one year and it was found that the study participants had 2.7 \pm 0.9 episodes per year on an average. Majority of the study participants had normal vital parameters and were afebrile. Half of the participants $(n=41$, $50 \%)$ were obese $\left(\mathrm{BMI}>23 \mathrm{Kg} / \mathrm{m}^{2}\right)$.

Table 1 Characteristics of Enrolled Patients

\begin{tabular}{|c|c|c|}
\hline CHARACTERISTICS & FREQUENCY & PERCENTAGE \% \\
\hline $\begin{array}{l}\text { AGE } \\
\begin{array}{l}<50 \text { yrs } \\
50-69 \text { yrs } \\
70-79 \text { yrs } \\
>80 \text { yrs }\end{array}\end{array}$ & $\begin{array}{l}23 \\
46 \\
12 \\
1\end{array}$ & $\begin{array}{l}28 \\
56 \\
14 \\
1.2\end{array}$ \\
\hline $\begin{array}{l}\text { SEX } \\
\text { Male } \\
\text { Female }\end{array}$ & $\begin{array}{l}38 \\
44\end{array}$ & $\begin{array}{l}46.3 \\
57.3\end{array}$ \\
\hline $\begin{array}{r}\text { Mmrc } \\
1 \\
2 \\
3 \\
4\end{array}$ & $\begin{array}{l}0 \\
20 \\
26 \\
36\end{array}$ & $\begin{array}{l}0 \\
24.4 \\
31.7 \\
43.9\end{array}$ \\
\hline $\begin{array}{c}\text { Exacerbations in a Year } \\
1 \\
2 \\
3 \\
4 \\
5\end{array}$ & $\begin{array}{l}2 \\
38 \\
25 \\
13 \\
4\end{array}$ & $\begin{array}{l}2.4 \\
46.3 \\
30.5 \\
15.9 \\
4.9\end{array}$ \\
\hline $\begin{array}{l}\text { Smoking } \\
\text { Never Smoker } \\
\text { Current Smoker } \\
\text { Former Smoker }\end{array}$ & $\begin{array}{l}49 \\
10 \\
23\end{array}$ & $\begin{array}{l}60 \\
12 \\
28\end{array}$ \\
\hline $\begin{array}{l}\text { Vaccination } \\
\text { Influenza } \\
\text { Pneumococcal }\end{array}$ & $\begin{array}{l}81 \\
11\end{array}$ & $\begin{array}{l}98.8 \\
13.4\end{array}$ \\
\hline $\begin{aligned} \text { BMI } & \\
& <23 \\
& >23\end{aligned}$ & $\begin{array}{l}41 \\
41\end{array}$ & $\begin{array}{l}50 \\
50\end{array}$ \\
\hline $\begin{array}{l}\text { Clubbing } \\
\text { No Clubbing } \\
\text { Grade } 1 \\
\text { Grade } 2 \\
\text { Grade } 3\end{array}$ & $\begin{array}{l}23 \\
4 \\
21 \\
34\end{array}$ & $\begin{array}{l}28 \\
4.9 \\
25.6 \\
41.5\end{array}$ \\
\hline $\begin{array}{c}\text { No of Lobes -HRCT } \\
1 \\
2 \\
3 \\
4\end{array}$ & $\begin{array}{l}13 \\
21 \\
24 \\
24\end{array}$ & $\begin{array}{l}15.85 \\
25.61 \\
29.27 \\
29.27\end{array}$ \\
\hline $\begin{array}{l}\text { Organisms } \\
\text { Pseudomonas } \\
\text { E.coli } \\
\text { No growth }\end{array}$ & $\begin{array}{l}6 \\
3 \\
73\end{array}$ & $\begin{array}{l}7.3 \% \\
3.65 \% \\
89\end{array}$ \\
\hline $\begin{array}{l}\text { BSI Score } \\
\text { Mild } \\
\text { Moderate } \\
\text { Severe }\end{array}$ & $\begin{array}{l}7 \\
19 \\
56\end{array}$ & $\begin{array}{l}8.5 \\
23.2 \\
68.3\end{array}$ \\
\hline $\begin{array}{l}\text { SGRQ Score } \\
\quad \text { Symptoms } \\
\text { Activity } \\
\text { Impact }\end{array}$ & & $\begin{array}{l}57 \\
49 \\
37\end{array}$ \\
\hline
\end{tabular}

As per the BSI score the number of lobes involved is classified as $<3$ and $>3$. Accordingly, in the present study $41.5 \% \quad(n=34)$ of the patients had involvement of 1-2 lobes in HRCT and 58.5\% $(n=48)$ had involvement of more than 2 lobes in HRCT. The mean BSI score obtained by the study subjects $(n=82)$ was $10.63 \pm 4.26$. The study participants $(68.3 \%)$ were classified as severe bronchiectasis as per BSI scoring. The mild and moderate categories were $8.5 \%$ and $23.2 \%$ respectively. (Fig 1)

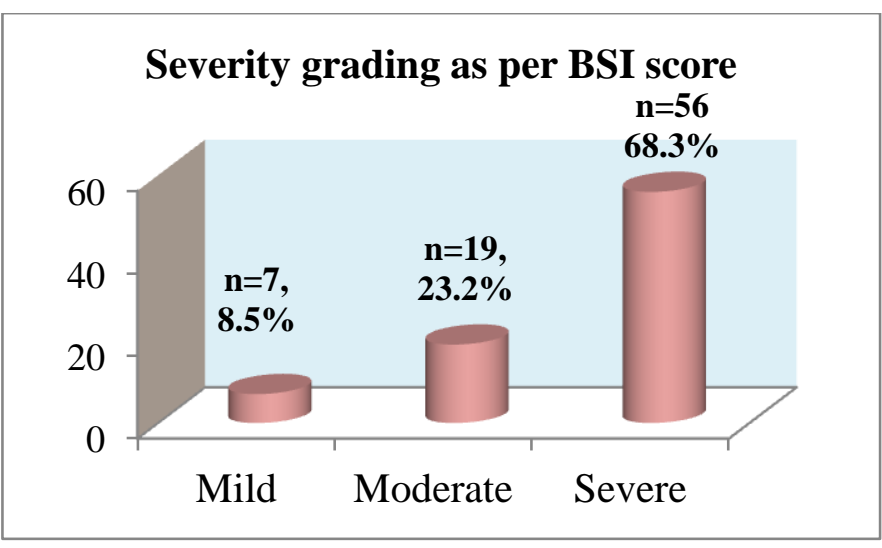

Fig 1

The St George Respiratory Questionnaire has weighted responses for symptoms, activity and impacts. St. George Respiratory Questionnaire was translated in local language and self-administered to the patients. The given table below shows the statistical values for the symptom score, activity score and impact score. (Table 2)

Table 2

\begin{tabular}{|l|c|c|c|c|}
\hline SGRQ scores & Minimum & Maximum & Mean & Std. Deviation \\
\hline Symptoms score & 110.0 & 549.5 & 327.6 & 86.6 \\
\hline Symptoms score \% & 14.0 & 97.0 & 57.1 & 16.0 \\
\hline Activity score & & & & \\
\hline Activity score \% & 146.5 & 982.0 & 490.3 & 167.7 \\
\hline Impact score & 14.0 & 100.0 & 49.7 & 17.0 \\
\hline Impact score \% & 221.6 & 1196.0 & 619.2 & 241.6 \\
\hline Total score & 10.2 & 72.3 & 37.0 & 14.7 \\
\hline Total score \% & 525.5 & 2559.0 & 1436.2 & 449.3 \\
\hline
\end{tabular}

The BSI and The St George Respiratory Questionnaire was correlated. 


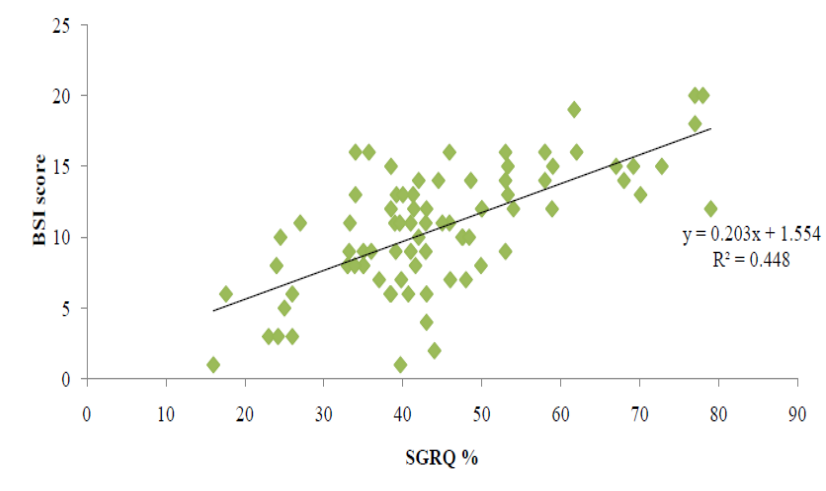

Fig 2

The above figure indicates that there was a highly significant correlation between the BSI score and the SGRQ score percentage. (Fig 2)

\section{Discussion}

The severity of bronchiectasis in the present study was determined by BSI score and then correlated with health-related quality of life (QOL) measurement using SGRQ questionnaire. The study included 82 patients with clinical and radiological evidence of bronchiectasis and their severity index were correlated to health-related quality of life scores. As mentioned earlier there is a propensity of increased severity in the elderly age group. In the present study, majority of the study participants belonged to the 50 -69 years age group (56.1\%). There was less representation of older age group (>70 years) in the study sample (15.8\%). There were a comparatively higher proportion of female participants $(57.3 \%)$ with bronchiectasis included in the study compared to the males $(46.3 \%)$. There was no significant $(\mathrm{p}=0.57, \mathrm{df}=3)$ variations in age distribution between males and females. The mean age of the study participants was $55.6 \pm 14.7$ years. In the study done by Minov et al. ${ }^{[4]}$ the mean age of the included participants was $63.4 \pm 8.1$ years. The study clearly indicated that no particular gender had major participation and this was to ensure no bias in testing the severity scores based on gender induced quality of life variations. Majority of the study subjects had MMRC breathlessness grades III and IV $(75.6 \%, \mathrm{n}=62)$ when compared to the lower grades indicating that there was more parenchymal damage or obstructive airway disease for most of the participants. This clearly indicated that the participants had moderate to severe exacerbations throughout the year. Accordingly, in the present study $41.5 \%(n=34)$ of the patients had involvement of 1-2 lobes in HRCT and 58.5\% ( $\mathrm{n}=48)$ had involvement of more than 2 lobes in HRCT. This is concordance with the clinical parameters which showed that severity increased as the number of lobes involved increased resulting in hypoxia reflected as clubbing and more severely corpulmonale. The study results clearly showed that there was a highly significant $(\mathrm{p}<0.001)$ improvement in all the spirometry parameters except FVC $(\mathrm{P}=0.06)$. The percentage change pre and post-bronchodilator in FeV1 was $9.12 \pm 3.5 \%$. The discrepancies in the pulmonary function test spirometry parameters can be influenced by various factors including age and stage at diagnosis.

The Bronchiectasis Severity Index incorporates 9 variables including age, Body mass index (BMI), FEV1 \% predicted, hospital admission in previous year, exacerbations in previous year, dyspnoea scale by MRC, Pseudomonas aeruginosa colonization, and colonization with other microorganisms. The severity is classified viz: Mild: $\leq 4$; moderate: $5-8$ and severe: $\geq 9$. The study participants obtained scores ranging from 1 to 20. The mean BSI score obtained by the study subjects $(n=82)$ was $10.63 \pm$ 4.26. In the previous study by Rosales-Mayor et $a l .{ }^{[5]}$, the mean BSI score among those with lesser exacerbations was $7.9 \pm 4.6$ and those with frequent exacerbations were 13.2 \pm 4.0 . This again had consensus with the mean BSI score $(10.63 \pm 4.26)$ obtained in our study showing that the severity of our study participants was moderate to severe as per BSI. The characteristic feature of our study was most of the study participants $(68.3 \%)$ were classified as severe bronchiectasis as per BSI scoring. The mild and moderate categories were $8.5 \%$ and $23.2 \%$ respectively. In the study by RosalesMayor et al. ${ }^{[5]}$, the proportion of mild, moderate and severe bronchiectasis were $25 \%, 32 \%$ and $43 \%$ respectively which was not similar to that obtained in our study. Yet another study by Minov et al. ${ }^{[4]}$, the severity index showed that $70 \%$ were severe 
followed by $20 \%$ moderate and $5 \%$ mild which was similar to our study. St. George respiratory Questionnaire scores (SGRQ) is a health-related QOL questionnaire used in the present study for estimating the QOL among the patients suffering from bronchiectasis. There was a highly significant correlation between the BSI score and the SGRQ score percentage $(p<0.001)$. In the SGRQ validation study by Weatherall et $a l^{[6]}$, the spirometry evaluation and severity classification by GOLD were taken into consideration. The validation proved that SGRQ QOL scores increased and show significant correlation as the severity of bronchiectasis increased. The study was able to prove that as the severity score as measured by BSI increased, there was a decline in QOL as measured by the increasing trend of mean SGRQ scores in various gradations of BSI scores. The present study is a prototype comparing the severity indices namely BSI with SGRQ which was unique compared with the available literature.

\section{Conclusion}

The study documented the socio-demographic profile of patients with bronchiectasis. As the severity scores increased as measured by BSI score, there was a derangement in the quality of life as per the St. George Respiratory Questionnaire. This study demonstrated a positive correlation between severity of bronchiectasis and quality of life of the patients suffering from bronchiectasis.

\section{References}

1. Wilson R, 1996 undefined. The biology of bacterial colonization and invasion of the respiratory mucosa. Eur Respir Soc [Internet]. [cited 2018 Aug 26]

2. Chalmers JD, Goeminne $\mathrm{P}$, Aliberti S, McDonnell MJ, Lonni S, Davidson J, et al. The Bronchiectasis Severity Index. An International Derivation and Validation Study. Am J Respir Crit Care Med [Internet]. 2014 Mar [cited 2018 Aug 26];189(5):576-85.
3. Jones P, Quirk F, medicine CB-R, 1991 undefined. The St George's respiratory questionnaire. resmedjournal.com [Internet]. [cited 2018 Aug 26]

4. Minov J, Karadzinska-Bislimovska J, Vasilevska K, Stoleski S, Mijakoski D. Assessment of the Non-Cystic Fibrosis Bronchiectasis Severity: The FACED Score vs the Bronchiectasis Severity Index. Open Respir Med J [Internet]. 2015 Mar 31 [cited 2018 Aug 17];9(1):46-51

5. Rosales-Mayor E, Polverino E, Raguer L, Alcaraz V, Gabarrus A, Ranzani O, et al. Comparison of two prognostic scores (BSI and FACED) in a Spanish cohort of adult patients with bronchiectasis and improvement of the FACED predictive capacity for exacerbations. PloS one. 2017;12(4): e0175171

6. Weatherall M, Marsh S, Shirtcliffe P, Williams M, Travers J, Beasley R. Quality of life measured by the St George's Respiratory Questionnaire and spirometry. European Respiratory Journal. 2009 May 1;33(5):1025-30. 